\title{
Methodological approach to assess tractor stability in normal operation in field using a commercial warning device
}

\author{
V. Rondelli, ${ }^{1}$ R. Martelli, ${ }^{1}$ C. Casazza, ${ }^{1}$ A. Guarnieri ${ }^{1}$ \\ ${ }^{1}$ Department of Agricultural and Food Sciences, University of Bologna, IT; Dipartimento di Scienze \\ e Tecnologie Agro-Alimentari, Università di Bologna, Italy
}

\section{Abstract}

Since Roll-0ver Protective Structures (ROPS) are mandatory on tractors, the number of fatalities caused in the event of an upset is definitely reduced. Nevertheless, fatal accidents caused by machine loss of stability are still of great concern. In fact, despite ROPS have reduced injury to agricultural operators, tractor stability is still a complex issue due to its high versatility in use, especially considering normal operations in field, when interactions with the environment such as soil morphology and climatic conditions are involved, as well as interactions with operator skills and experience.

With the aim of collecting data on different variables influencing the dynamics of tractors in field, a commercial device that allows the continuous monitoring of working conditions and the active configuration of the machines was fitted on standard tractors in normal operation at the experimental farm of the Bologna University.

The device consists of accelerometers, gyroscope, GSM/GPRS, GPS for geo-referencing and a transceiver for the automatic recognition of tractor-connected equipment. A microprocessor processes data and provides information, through a dedicated algorithm requiring data on the geometry of the tested tractor, on the level of risk for the operator in terms of probable loss of stability and suggests corrective measures to reduce the potential instability of the tractor.

\section{Introduction}

Tractors are the most widely used machines in agriculture and are responsible for the high number of fatalities related to the use of farm machinery (McCurdy and Carroll, 2000; Nichol et al., 2005). In Italy,

\footnotetext{
Correspondence: Valda Rondelli, Dipartimento di Scienze e Tecnologie AgroAlimentari, Università di Bologna, via G. Fanin 50, 40127 Bologna, Italy. Tel. +39.051.766632 - Fax: +39.051 .765318 .

E-mail: valda.rondelli@unibo.it
}

Key words: accident prevention, operator safety, rollover tractor, warning device.

(C) Copyright V. Rondelli et al., 2013

Licensee PAGEPress, Italy

Journal of Agricultural Engineering 2013; XLIV(s2):e132

doi:10.4081/jae.2013.s2.e132

This article is distributed under the terms of the Creative Commons Attribution Noncommercial License (by-nc 3.0) which permits any noncommercial use, distribution, and reproduction in any medium, provided the original author(s) and source are credited. data reported by ISPESL (National Institute for Occupational Safety and Prevention) indicate a high number of fatal accidents associated with the use of tractors, 114 in 2008 and 149 in 2009 (Fargnoli et al., 2010). Despite the mandatory application of ROPS to provide a survival volume for the operator, accidents due to tractor rollover are the leading cause of death in farm operations (Pessina and Facchinetti, 2011).

The analysis of tractor upsets is complex because the rollover is influenced by several factors such as interaction among operator, tractor and environment. Major crit ical variables reducing tractor stability are slopes and rough terrain; these factors interact in a complex manner in determining the risk of rollover, influenced by the position of the tractor's centre of gravity, forward speed and turning angle.

In addition, safe tractor operation also depends on operator skill and experience, reaction time, etc. Interacting factors affect the operator's percepti on of hazard, using his skill and intuition to evaluate the effects of different environmental factors (Murphy et al., 1985). While most experienced tractor operators have developed an intuitive feel in perceiving hazardous situations, there are many inexperienced young or casual workers who have no specific training in driving the tractor safely (Nichol et al., 2005). Furthermore, the ability to op erate safely is further reduced by adverse stressors as vibrations, noise, cold and heat and this is particularly significant when stressor conditions drag on as occurs frequently during farming (Murphy et al., 1985). Other aspects affecting upsets are the characteristics of implements coupled to the tractor

Devices have been developed to inform the operator about tractor stability and warn him in case of overturn risk (Mitchell et al., 1972; Spencer and Owen, 1981) or to alert medical assistance in case of accident (Sarghini and D'Urso, 2010). Frequently, devices evaluating tractor stability conditions take into account mathematical models based on the forces acting on the tractor that can cause the upset. Both the constructive aspects of the tractor, such as weight or the position of the centre of $g$ ravity, and those related to its movement such as speed, turning radius and slope are taken into account. Murphy et al. (1985) developed a mathematical model to measure the relative stability of a tractor considering weight and centrifugal force vectors and the effects of ground roughness.

Active systems have been evaluated to stop the tractor in case of rollover risk by cutting fuel supply or ignition system (Murphy et al., 1985). Nichol et al., (2005) developed a low cost device based on sensors and a display to inform the tractor operator of possible instability and to assist him in avoiding dangerous situations. Etzler et al. (2008) proposed a methodology for establishing a risk threshold to inform the tractor operator and assist him in performing corrective manoeuvres for mitigating risks acco rding to risk level. However, only very few commercial warning systems have been developed nowadays and additional research needs to be carried out to assess their performance on tractors operating in farms.

A low-cost commercial warning device (COBO International, USA) is currently under evaluation. The device is fitted with sensors to detect tractor dynamic properties and, through a predictive mathe - 
matical model, process a risk index to inform the operator of potential tractor instability and suggest corrective measures to avoid dangerous operations.

Research objectives are to: i) assess the performance of the commercial device on tractors as they operate in field; ii) collect data on different variables influencing the dynamics of the tractors; iii) verify if the device can be used to improve the operator's risk perception.

Preliminary and methodological aspects of the research are described, providing information on the architecture of the device, tractor field testing and data collection.

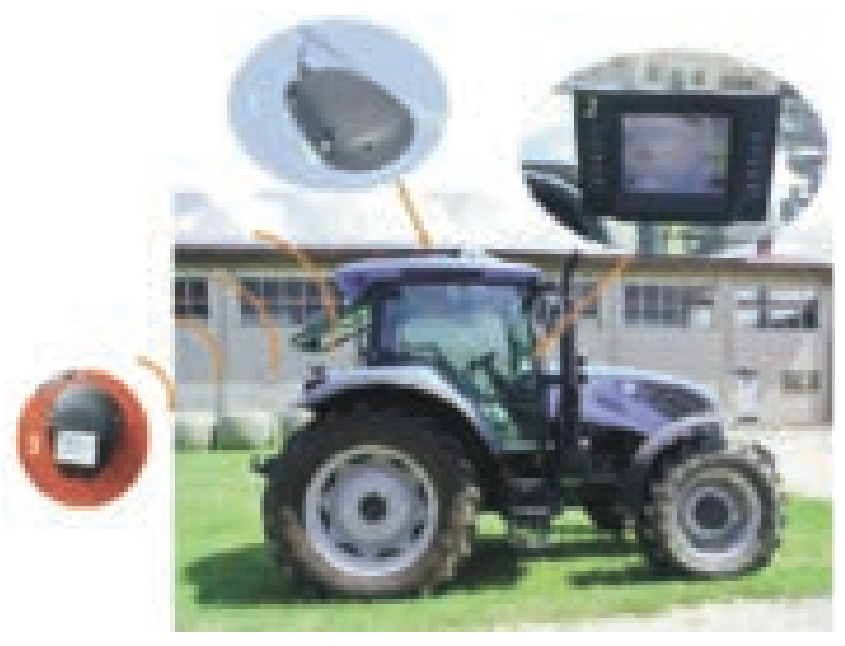

Figure 1. Tractor fitted with multisensor device, main controller (1), visual warning display (2), implement transceiver (3).

\section{Multisensor device}

The commercial warning device (COBO International, USA) for tractor stability prediction consists of the following units:

- dual-axis accelerometer as tilt sensor and tri-axial accelerometer to validate the signals from the bi-axial accelerometer and confirm tractor overturn;

- microprocessor to acquire signals and process information;

- gyroscope to measure tractor steering angle rate;

- GPS for tractor geographical localization;

Table 1. Parameters recorded by sensors.

\begin{tabular}{|c|c|c|}
\hline Parameter & Units & Notes \\
\hline Speed & $\mathrm{km} \mathrm{h}^{-1}$ & \\
\hline Elevation & $\mathrm{m}$ & above sea level \\
\hline \multirow[t]{2}{*}{ Roll angle } & degree & $>0$ upward \\
\hline & & $<0$ downward \\
\hline \multirow[t]{2}{*}{ Pitch angle } & degree & $>0$ clockwise with respect to the advancing direction \\
\hline & & $<0$ anticlockwise with respect to the advancing direction \\
\hline Steering & $\operatorname{rad~s}^{-1}$ & $>0$ clockwise with respect to the advancing direction \\
\hline
\end{tabular}

Table 2. Tractors, engine power and working areas.

\begin{tabular}{llll} 
Tractor code & Power $(\mathrm{kW})$ & Area & Field operations \\
1 & 107 & hill & harrowing, mowing \\
2 & 74 & hill & baling, liquid manure spreading \\
\hline 3 & 200 & plain + hill & plowing \\
4 & 103 & plain & subsoiling, harrowing, baling \\
\hline 5 & 63 & plain & mowing, hay making \\
\hline
\end{tabular}

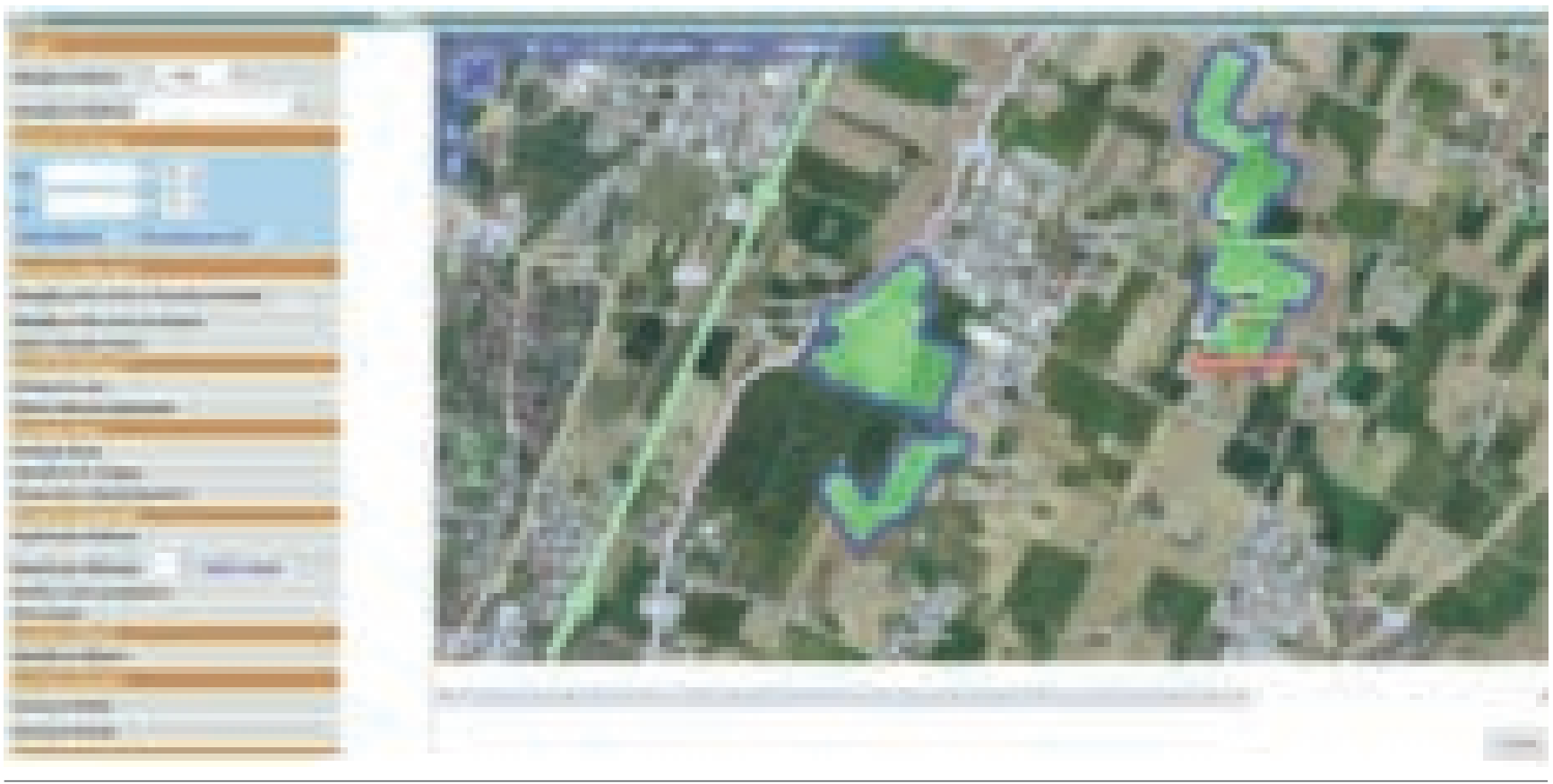

Figure 2. Website overview, mapped areas and tractors monitored during operations. 


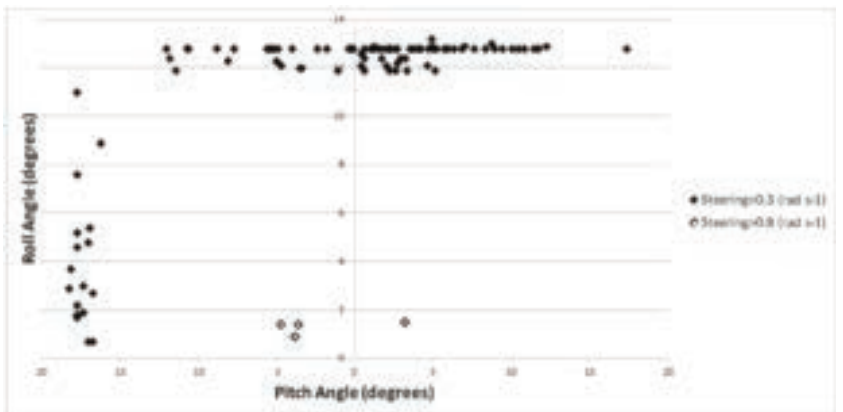

Figure 3. Values of the parameters for warning cases.

Table 3. Automatically recognized operating machinery.

\begin{tabular}{|ccc}
\hline Transceiver code & Implement & Working area \\
\hline 86 & mower & hill \\
87 & tedder & hill \\
\hline 88 & liquid manure spreader & hill \\
89 & round baler & hill \\
\hline 90 & rotary cultivator $(3 \mathrm{~m}$ width $)$ & plain + hill \\
91 & rotary cultivator $(4 \mathrm{~m}$ width) & plain \\
\hline 92 & harrow & plain \\
\hline 93 & subsoiler & plain \\
\hline 94 & mower conditioner & plain \\
95 & plough & plain + hill \\
\hline 96 & cultivator & hill \\
97 & round baler & plain \\
\hline
\end{tabular}

- GSM/GPRS quad-band module for data transmission.

In addition, the multisensor unit recognizes the implements coupled to the tractor by means of a $2.4 \mathrm{GHz}$ transceiver installed on the implements.

The device is completed by a visual warning system based on a mathematical model to alert the operator on rollover risk level (Figure 1).

The risk index, based on a simplified quasi-static model, considers both the geometric parameters of the tractor, or the complex tractor-implement (its overall weight and distribution, centre of gravity, track and wheelbase), and the dynamic operating conditions detected by the sensors (speed, roll and pitch angles, steering rate).

The warning device must be installed by the manufacturer technical staff in order to set up the device, acquiring tractor mass, wheelbase, track and ballasts. The weight of both tractor axles and the overall weight are achieved on the horizontal plane and on a slope in the 8-15 degree range. Weighing is repeated with all implements coupled to the tractor.

The multisensor unit is normally fixed on the tractor roof to be perfectly horizontal, while the visual warning display is fitted on the tractor cab to be monitored from the driver's seat. The device is complemented by a dedicated website, which allows to geo-reference the farm parcels and record tractor types, operators and implements.

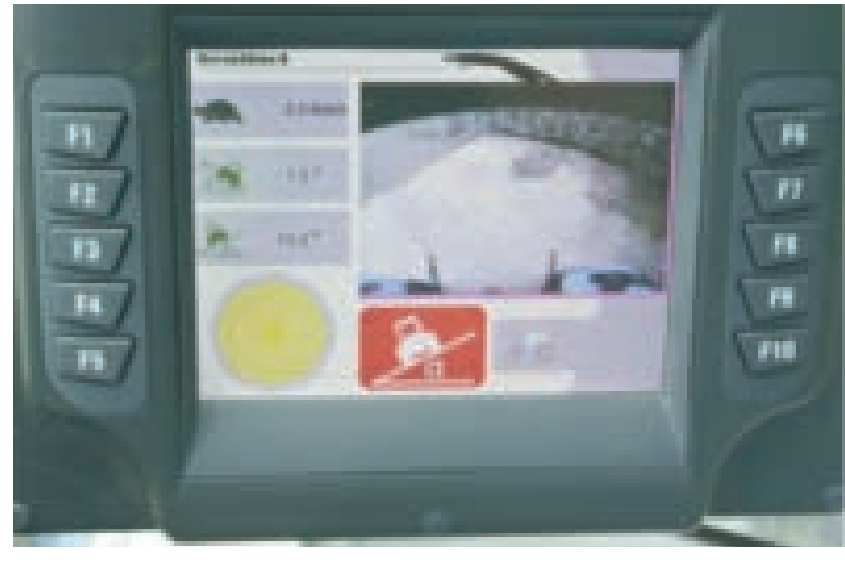

Figure 4. Multisensor display device during the static test.

Signals detected by sensors (Table 1) are transferred automatically to a database accessible online. Data could be filtered by queries to limit the analysis to interesting information; these could be downloaded as spreadsheets for later evaluation.

Laboratory tests were performed for the device evaluation before field testing. The multisensor was placed on a standard wheeled tractor and this was statically tested on a slope fitted with a commercial digital level. The roll angle was changed and the two different readings were compared. The output of the device was deemed correct.

\section{Field tests}

Five warning devices have been installed on standard tractors in use at the experimental farm of the University of Bologna. The monitored machinery includes modern four-wheel drive tractors fitted with a ROPS cab and engine power in the 60 to $100-\mathrm{kW}$ range to carry out normal farm operations (Table 2).

Twelve implements coupled to the tested tractors have been fitted with transceivers for automatic detection (Table 3 ).

The experimental farm is mainly cultivated with cereal and fodder crops. Fields are located partly in Cadriano, a flat area with altitude in a range of 19 to $40 \mathrm{~m}$ above sea level, and partly in Ozzano, in a hilly area with altitude up to $370 \mathrm{~m}$ above sea level.

Ten parcels (five on level ground and five on hill) corresponding to the farm's main production units were mapped and recorded on the website to check online the location of the tractors involved in the test (Figure 2). Ten other areas could be mapped as highly hazardous and the device could be set up to alert the operator when the tractor approaches these zones, reaching maximum signal intensity on crossing these boundaries. This function was not checked in the field test.

The five tested tractors were driven by operators employed in the experimental farm and experienced in tractor driving. Tests were arranged to keep the operators in their usual working area, with the exception of the operator driving tractor 3 (Table 2) who usually operated on level ground, but during tests also worked on hills to compare his risk perception in an unusual working area (Table 2).

In addition to the signal detected by the sensor, a data collection form was given to the operators involved in the test, to be filled in after completing the activity to report the operation performed, the working time and the number of events considered potentially dangerous on the basis of a pre-defined scale of estimated risk level. The compiled forms will allow comparing the operators' responses with information provided by the multisensor. 


\section{Preliminary results and considerations}

The availability of a commercial low cost device, such as the tested warning device, offers the advantage of retrofitting it on tractors. In European Countries since 1974, according to EC Directive 74/150 (EEC, 1974), tractors are fitted with ROPS as a passive means to minimize the risk of injury for drivers in the event of tractor upset. The approach to fit a ROPS was the consequence of verifying that there was only a little chance of preventing tractors from rolling over (Moberg, 1973). Nonetheless, a warning device capable of informing the tractor operator on the stability of his machine during operation could greatly contribute to prevent fatal accidents because he can promptly react and consequently decrease dangerous situations.

The potential of the tested device has positive effects on the operator, with respect to the improvement of the risk perception associated with the stability of the machine, but also offers the employer the chance to evaluate the safety level in the farm through automatic monitoring of fleet equipment, mechanical operations, working areas and dynamic operational conditions.

An experimental methodology was presented at this preliminary stage of research, based on an integrated information system to allow safety evaluation in farm operations. Tests were planned on fields with wideranging orographic variability but all tested machinery is modern and operators are experienced. The aim is to monitor tractors in routine operating conditions but with different levels of risk in relation to different land slopes and different working conditions.

The multisensor system, combined with the dedicated web site, allow the recording of events potentially at a risk level above a specific threshold. These records provide the time history of risk events encountered during operations and it is then possible to evaluate the temporal and spatial distribution of the events, analyzing possible causes and comparing the level of safety of the same operation performed by different drivers in different orographic conditions.

Figure 3 shows data of preliminary field tests. Values of pitch and roll angles are displayed when the warning device alerted the operator of tractor 1 during harrowing operation. This activity has been selected because of the high frequency of alarm signals. Absolute values of roll angle are shown due to the symmetrical position of the machinery centre of gravity. Two sets of data are presented, one corresponding to data of steering less than $0.3 \mathrm{rad} \mathrm{s}-1$ and the other higher than $0.8 \mathrm{rad} \mathrm{s}-1$, to point out the prevalent cause, pitch angle, roll angle or steering, that led to the warning.

Clearly the performance of the device in field must first of all be assessed in order to verify the correctness of the sensors' output. The warning device was checked statically in the lab and the results confirmed the acceptable performance of the tilt sensors. However, in field the addition of different forward speeds, different slopes and different steering speeds can interfere with data detected by the sensors. In fact, since many operations are performed with the tractor in field, the device should be able to correctly measure roll and pitch angles at different forward speeds and steering speeds, which means assessing the tractor during normal operation.

It must be underlined that the warning system was designed to help the operator in case of a potential rollover situation suggesting him to act on the parameters under his control, such as speed and turning radius.

Figure 4 shows the display device during the static test. Many indications are provided: speed, pitch and roll angles, warning signal represented by the yellow concentric circles and the condition of prevailing risk, with the suggestion of a corrective action, in the red box. The larger box shows the recording of a device integrated camera.

The operator needs to recognize the dangerous situation on time to correct it and avoid the fatal event. If the device detects the risk level correctly, it can improve operator perception in potentially unstable situations. In this regard it is very important to check whether the display warns too often about potential rollover situations because this can lead the operator to ignore the warning. The levels at which the display shows a near rollover condition need to be optimized to keep the operator's attention.

\section{References}

Etzler L., Marzani S., Montanari R., Tesauri F. 2008. Mitigating accident risk in farm tractors.

Ergon. Des. 16:6-13.

European Commission. Commission decision of 4 March 1974 on the approximation of the laws of the Member States relating to the type-approval of wheeled agricultural and forestry tractors, 74/150/EEC. Available on: www/eur-lex.europa.eu.

Fargnoli M., Laurendi V., Tronci M. A risk assessment procedure for the users of narrow track tractors. Proceedings of the 2nd Ragusa SHWA Int. Conf., 2010 Sept. 16-18, Ragusa, Italy.

McCurdy S.A., Carroll D.J. 2000. Agricultural injury. Am. J. Ind. Med. 38:463-80.

Mitchell B.W., Zachariah G.L., Liljedhal J.B. 1972. Prediction and control of tractor stability to prevent rearward overturning. Trans. ASAE 15:838-44.

Moberg, H.A. 1973. Dynamic testing of tractor protection cabs: Development of method, practical experiences. SAE Paper No. 73076. Warrendale, Pa.: SAE

Murphy D.J., Beppler D.C., Sommer H.J. 1985. Tractor Stability Indicator. Appl. Ergon. 16:187-91.

Nichol C.I., Sommer III H.J., Murphy D.J. 2005. Simplified overturn stability monitoring of agricultural tractors. J. Agric. Saf. Health. 11:99-108.

Pessina D., Facchinetti D. Il ruolo del web nel monitoraggio degli incidenti mortali dovuti al ribaltamento dei trattori agricoli. Proceedings of the Conference: Gestione e Controllo dei Sistemi Agrari e Forestali, 2011 Sept. 22-24, Belgirate, Verbania, Italy.

Sarghini F., D'Urso G. An early warning device for identification of tractor accidents, rapid alert and assistance. Proceedings of the 2nd Ragusa SHWA Int. Conf., 2010 Sept. 16-18, Ragusa, Italy.

Spencer H.B., Owen G.M. 1981. A Device for Assessing the Safe Descent Slope of Agricultural Vehicles. J. Agr. Eng. Res. 26:277-86. 